for other circumstances, could conceivably account for the whole effect. If atmospheric haze be proved insufficient, it is alternatively suggested that the differential effects may possibly be accounted for by assuming the production of a spectrum of non-rotating matter in the solar atmosphere.

The Ninth Satellite of Jupiter.-An investigation of the ninth satelite of Jupiter has led Messrs. Nicholson and Shapley to estimate its diameter as lying between Ix and $\mathrm{I}_{7}$ miles (The Observatory, vol. xl., p. 107). From photographs of this tiny object taken with the 6o-in. reflector at Mt. Wilson, the photographic magnitude at mean opposition was found to be 18.6 , as compared with 17.5 and 18.0 for the seventh and eighth satellites respectively. Allowing for a probable colour-index of one magnitude, the angular diameter of the ninth satellite at mean opposition works out at $0.006^{\prime \prime}$ or $0.009^{\prime \prime}$, according to the value adopted for the visual albedo, and these lear to the limits of diameter stated above.

\section{GERMANY'S EFFORT TO OBTAIN NITROGENOUS COMPOUNDS.}

$\mathrm{A}^{1}$ THOUGH elementary nitrogen is not only useless, but positively antagonistic, to the life of plants and animals (except to that of some bacteria which take free nitrogen from the atmosphere and convey it to the ronts of leguminous plants), combined nitrogen is absolutely necessary for their metabolism. Animals obtain nitrogen from the vegetables they consume, plants from the nitrogenous constituents of the soil. The soil obtains part of its combined nitrogen from decaying vegetable matter and from the waste products of animals; the remainder has to be added. The two chief forms in which it is added are sodium nitrate and ammonium sulphate, which to a large extent are interchangeable. But for the manufacture of explosives sodium nitrate is absolutely necessary and ammonium sulphate useless. Germany, foreseeing that its supply of Chilean nitrate would be cut off by the blockade of the British Fleet, was faced with irremediable disaster unless it could lay in a sufficient stock before declaring war, or devise methods of synthesising nitric acid. The manner in which this difficulty has been overcome is described by Prof. Camille Matignon in the Revue générale des Sciences (January $\mathrm{I}_{5}$ and 30 ). Before the war Germany was the greatest consumer of combined nitrogen. In $\mathrm{I}^{1} \mathrm{I}_{3}$ the consumption amounted to 750,000 tons of Chilean nitrate, 35,000 tons of Norwegian nitrate, 46,000 tons of ammonium sulphate, and 30,000 tons of cyanamide. In $19 I^{1} 3$ great efforts were devoted in Germany to the preparation of materials necessary for war, and no attempt was made to conceal them. The German Ammonium Sulphate Syndicate had a reserve of 43,000 tons, and on the declaration of war there was probably a stock of Ioo,ooo tons of Chilean nitrate. Immediately after the battle of the Marne, when a long war was evidently certain, the production of artificial nitrates and of ammonium sulphate was stimulated, the Badische Aniline Company and Bayer and Co. being subsidised t) the extent of $30,000,000$ marks for the installation of factories to convert ammonia into nitric acid. In peace time 550,000 tons of ammonium sulphate were produced annually in Germany, but this output was reduced once war was declared. As this substance is a by-product in the manufacture of gas and cast-iron, people in Germany were instigated to use gas and coke instead of coal, and by such means an annual output of 250,000 tons of ammonium sulphate was attained. The problem of converting the ammonia into nitric acid was solved by the Frank and Caro and the Kayser processes. A French chemist, Kuhlmann, had discovered that ammonia is oxidised to nitrogen peroxide when mixed with air and passed over warm, finely divided platinum. The reaction was employed on a commercial scale by Ostwald, and improved both by Kayser and by Frank and Caro. By the end of 1915 the Anhaltische Maschinenbau Society of Berlin had established thirty installations for the conversion by Frank and Caro's process, and these had a capacity of more than I00,000 tons of nitric acid per month. But this was. only one of the methods adopted. Given a cheap. source of electrical energy, it was known to be commercially practicable to prepare nitric acid by the direct oxidation of nitrogen in the electric flame, and this process had been established in Norway by Birke. land and Eyde, who used the waterfalls as a source of energy. The Germans have established a factory employing Pauling's process (a modification of that. of Birkeland and Eyde) at Muhlenstein, in Saxony, in the neighbourhood of the lignite beds, which form the source of energv, and this has an annual output of 6000 tons of nitric acid.

The third principal method adopted for the preparation of combined nitrogen was the direct synthesis of ammonia. Bosch and Mittasch, two chemical engineers of the Badische Company, had adapted Haber's synthesis to industrial conditions, and the company had established a factory with an annual output of 30,000 tons of synthetic ammonium sulphate. In April, I914, the company increased its capital in order to raise the output to 130,000 tons, and after the battle of the Marne it was subsidised by the German Government to increase the production to 300,000 tons.

Before the war the production of cyanamide in Germany was comparatively small, but it has increased largely under Government stimulus. The cyanamide manufacturers desired a monopoly, but this was opposed by the Badische and other companies and by the gas manufacturers, and the project seems to have been abandoned.

In the direction of the manufacture of manures, it was necessary to economise sulphuric acid, so ammonia was neuiralised with nitre cake, and the resulting mixture of sodium and ammonium sulphates was mixed with superphosphate. Moreover, it was found that superphosphate will absorb gaseous ammonia, and although the ca'cium acid phosphate is thereby converted into the inscluble tricalcic phosphate, it is formed in an easily assimilable condition. and the product is found by experience to act both as a nitrogen and phosphorus manure.

Prof. Matignon seems to be correct in claiming that chemistry has saved Germany from disaster.

E. H.

\section{SUBSIDENCE RESULTING FROM MINING.}

$T H E$ very important question of subsidence resulting from mining operations has recently been discussed in a bulletin issued by the Engineering Experiment Station of the University of Illinois. The report is prepared by Dr. L. E. Young, mining engineer for the Illinois Coal Mining Investigations, and Prof. H. H. Stock, professor of mining engineering in the University of Illinois, under a co-operative agreement between the University, as represented by its Engineering Experiment Station, the Illinois State Geological Survey, and the United States Bureau of Mines. Apparently, whilst we in this country oontent ourselves with talking about the need for closer co-

No. 247 I, VOL. 99] 
operation between the technical faculties of our universities and the industries concerned, in America such co-operation is already an established fact, and reports such as the present one show evidence of its value.

This bulletin is merely a preliminary one, presenting a complete and concise account of what is known up to the present on the subject of subsidences due to mining operations, and the authors have done their work in a most thorough and painstaking fashion, and have missed very little of the published information on the subject, in spite of the difficulty of bringing it together from the large number of scattered records through which it is disseminated. It need scarcely be said that the subject is one of the greatest importance in this country, where so many of our most densely populated industrial centres are situated upon the coalfields themselves. The problem whether large masses of coal should be left in the form of supporting pillars, and thus be permanently lost to the nation, or to what extent it is advisable to remove them, with the risk, or even with the certainty, of causing a certain amount of surface damage, is obviously one of first-rate importance, especially at times like the present, when the proper conservation and full utilisation of our natural resources demand our utmost attention.

Messrs. Young and Stock have contented themselves with summarising the theories on subsidence promulgated by various writers, notably the Belgian, French, Prussian, and Austrian theories; there cannot really be said to be any British or American theories, although various British engineers have proposed formulas, notablv for determining the angle of "draw," and the size of the coal pillars that must be left in order adequately to protect any given area of surface; the wide divergence of these various formulas is well shown by a diagram, reproduced from a paper by Prof. George Knox, which shows that some of these give results ten times as great as those given by others.

The introductory notice to the present bulletin suggests that the Illinois authorities propose to study the problem in a systematic fashion, by taking careful levels across selected groups of mines at regular intervals, and simultaneously noting the conditions of the underground workings, such observations to be continued for a number of years, when it may be hoped that it will be found possible to correlate surface subsidences and underground workings, and thus to obtain data that will enable the conditions of maximum economy to be determined. This is a subject that might with the greatest advantage be taken up on similar lines by one or other of the committees formed to deal with industrial research in this country.

H. L.

\section{FURTHER STUDIES IN PLANT GENETICS.}

THE September number of the American Naturalist (vol. 1., No. 597) is devoted to studies of inheritance in plants. Dr. H. H. Bartlett writes on "The Status of the Mutation Theory, with especial reference to CEnothera." $\mathrm{He}$ "finds incredible the arguments that have been brought forward in favour of the idea that mutation and Mendelian segregation are the same." Nevertheless, it still remains to be decided "whether or not mutation is always, or ever, conditioned by previous hybridisation." Dr. O. E. White describes some researches in continuation of Mendel's original subject-the inheritance of cotyledon colour in Pisum. Alleged differences between the colour of segregated seeds of the $\mathrm{F}_{2}$ generation and those of the original parents are attributed to environmental changes: yellow-cotyledon varieties may produce green seeds because of immaturity, absence of sunlight, or excess of moisture, while green-cotyledon varieties may fade to yellow or yellowish-green through excess of sunlight. In one variety-"Goldkönig" - with yellow cotyledons, the yellow colour is, contrary to the usual rule, recessive to green. This form "may be regarded as lacking both the factor for causing green pigment and the factor for causing that pigment to fade on the maturity of the seed." When "Goldkönig" is crossed with yellow-seeded varieties in which yellowness is dominant, the $F_{1}$ generation are all yellow-seeded, and the $\mathrm{F}_{2}$ generation are segregated in the proportion of three green to thirteen $(9+3+1)$ yellow.

"Inheritance of Sex in the Grape" is discussed by W. D. Valleau. Wild vines bear flowers which are functionally either male or female, but the carpels or pistils are respectively present in a reduced condition; the plants are thus transitional between the hermaphrodite and the dicecious form. Functional hermaphrodites, however, appear in cultivation. Breeding experiments suggest that "both the staminate and functionally pistillate vines carry the determiners for femaleness and maleness, respectively, partially suppressed."

The Journal of Genetics for September (vol. vi., No. I) is completely occupied by Prof. A. H. Trow's analysis of form and inheritance in the common groundsel (Senecio vulgaris). In a long paper he discusses the number of nodes and their distribution along the main axis in this species and its segregates. Dividing the families of plants studied into "low" (9-16 nodes), "medium" (18-26 nodes), and "high" (30-3I nodes), he finds that medium characters are dominant to both low and high, and infers, therefore, the existence of two pairs of alternative determinants. However, from the cross "medium" $\times$ "high" there emerge families with from $36-39$ nodes, forming a "very high" group; this "segregates out from "high" as a recessive." From the cross "low" $\times$ " high" other anomalous results were obtained, and the author foresees many years' work before definite conclusions can be reached. In a short paper Prof. Trow discusses the inheritance of "albinism" in groundsel; he finds that in some forms the expected ratio of green to white plants as $I_{5}$ to $I$ is obtained in the $F_{2}$ generation; in others it is unaccountably departed from.

\section{THE ORGANISATION AND DEVELOPMENT OF CHEMICAL INDUSTRY AND RE- SEARCH. ${ }^{2}$}

SOUTH AFRICA is a country which has hitherto $S$ existed, and still does at the present moment exist, on its rich stock of raw materials. Its exports, in addition to the raw products of agriculture, are chiefly metals, crude and unrefined, and diamonds uncut. The chief chemical industry is the preparation of raw gold bullion from the quartzitic ore of the Transvaal. This is carried out in three operations - the first being fine pulverisation by mechanical means; the second, amalgamation with mercury: and the third, solution of the unamalgamated gold still remaining by means of sodium cyanide solution, followed by reprecipitation with excess of zinc shavings and final treatment of the metal, so as to get rid of as much of the base metal present as possible before pouring into commercial bars. The major portion of the plant necessary for these operations consists of iron and steel, and the raw materials for their manufacture exist in comparative aburdance in the Transvaal. A thorough and scientificilly com-

1 From the presidential address delivered to Secrion B-Chemistry,
Geolngy, Metallurgy, Mineralogy, and Geography-of the South African Seolngy, Metallurgy, Mineralogv, and Geography-of the South African Association for the Advancement of Science at the Maritzburg meeting,
July 4, 19 6, by Prof. J. A. Wilkinson. NO. 247I, VOL. 99] 